\title{
Oesophageal balloon calibration during pressure support ventilation: a proof of concept study
}

\author{
Gianmaria Cammarota ${ }^{1} \cdot$ Federico Verdina ${ }^{2} \cdot$ Erminio Santangelo $^{2} \cdot$ Gianluigi Lauro $^{2} \cdot$ Ester Boniolo $^{2}$. \\ Riccardo Tarquini ${ }^{2}$. Elena Spinelli ${ }^{3} \cdot$ Marta Zanoni $^{1} \cdot$ Eugenio Garofalo ${ }^{4} \cdot$ Andrea Bruni $^{4}$. Antonio Pesenti ${ }^{3}$. \\ Francesco Della Corte ${ }^{2} \cdot$ Paolo Navalesi $^{4} \cdot$ Rosanna Vaschetto $^{2} \cdot$ Tommaso Mauri $^{3}$
}

Received: 19 September 2019 / Accepted: 28 November 2019 / Published online: 2 December 2019

(c) Springer Nature B.V. 2019

\begin{abstract}
Oesophageal balloon calibration improves the oesophageal pressure (Pes) assessment during invasive controlled mechanical ventilation. The primary aim of the present investigation was to ascertain the feasibility of oesophageal balloon calibration during pressure support ventilation (PSV). Secondarily, the calibrated Pes $\left(\mathrm{Pes}_{\mathrm{cal}}\right)$ was compared to uncalibrated one acquired at $4 \mathrm{ml}$-filling volume $\left(\mathrm{Pes}_{\mathrm{V} 4}\right)$, as per manufacturer recommendation. After a naso-gastric tube equipped with oesophageal balloon was correctly positioned in 21 adult patients undergoing invasive volume-controlled ventilation (VCV) for acute hypoxemic respiratory failure, the balloon was progressively inflated, applying a series of end-inspiratory and end-expiratory holds at each filling volume during VCV and PSV. Upon optimal balloon filling volume $\left(\mathrm{V}_{\text {best }}\right)$ was identified, Pes cal $_{\text {was }}$ computed by correcting the Pes measured at $\mathrm{V}_{\text {best }}$ for the oesophageal wall pressure elicited at same filling volume. Finally, end-expiratory and end-inspiratory $\mathrm{Pes}_{\mathrm{V} 4}$ were recorded too. A total of 42 calibrations, 21 per ventilatory mode, were performed. $\mathrm{V}_{\text {best }}$ was $1.9 \pm 1.6 \mathrm{ml}$ in VCV and $1.7 \pm 1.6 \mathrm{ml}$ in PSV $(\mathrm{p}=0.5217) . \mathrm{Pes}_{\mathrm{V} 4}$ was overestimated compared to Pes cal $_{\text {cal }}$ at end-expiration and end-inspiration ( $\mathrm{p}<0.0001$ for all comparisons) in both VCV $\left(13.4 \pm 3.4 \mathrm{cmH}_{2} \mathrm{O}\right.$ and $15.4 \pm 3 \mathrm{cmH}_{2} \mathrm{O}$ vs. $8.5 \pm 2.9 \mathrm{cmH}_{2} \mathrm{O}$ and $\left.11.4 \pm 3 \mathrm{cmH}_{2} \mathrm{O}\right)$ and $\mathrm{PSV}\left(14.7 \pm 4.2 \mathrm{cmH}_{2} \mathrm{O}\right.$ and $17 \pm 3.9 \mathrm{cmH}_{2} \mathrm{O}$ vs. $8.9 \pm 3.4 \mathrm{cmH}_{2} \mathrm{O}$ and $12.4 \pm 3.9$ $\mathrm{cmH}_{2} \mathrm{O}$ ). In PSV, oesophageal balloon calibration is feasible and allows to obtain a reliable Pes assessment compared to uncalibrated approach.
\end{abstract}

Keywords Manometry $\cdot$ Oesophagus · Artefacts $\cdot$ Artificial respiration

\section{Introduction}

Accurate measure of pleural pressure plays an important role in the advanced respiratory monitoring of patients undergoing mechanical ventilation in intensive care unit (ICU)

Gianmaria Cammarota

gmcamma@gmail.com

1 Anaesthesia and General Intensive Care, "Maggiore della Carità" University Hospital, Corso Mazzini18, 28100 Novara, Italy

2 Department of Translational Medicine, Università del Piemonte Orientale, Novara, Italy

3 Department of Anaesthesia, Critical Care and Emergency, Fondazione IRCCS Ca' Granda Ospedale Maggiore Policlinico, Milan, Italy

4 Department of Medical and Surgical Science, Università Magna Greacia, Catanzaro, Italy
[1-3]. The oesophageal pressure (Pes) is the most widely accepted measure to estimate the pleural pressure during controlled and assisted mechanical ventilation $[4,5]$. However, the reliability of Pes monitoring depends on several factors related to mechanical properties of the thoracoabdominal system [6,7], to the applied airway pressure, and to the model of oesophageal balloon employed [8]. Thus, a calibration procedure that could minimize the influence of confounding factors affecting Pes measurements might represent a useful achievement for clinical management of intubated patients [9]. Recently, it has been described that, in hypoxemic patients undergoing invasive controlled mechanical ventilation, a calibration technique improves the accuracy of Pes assessment [10]. Calibration consists of two stages aiming to (1) detect the optimal oesophageal balloon filling volume $\left(\mathrm{V}_{\text {best }}\right)$ and (2) correct Pes for the artefacts deriving from the oesophageal wall reaction and the elastic recoil of the balloon. The calibrated Pes $\left(\mathrm{Pes}_{\mathrm{cal}}\right)$, obtained 
following this procedure [10], leads to a more accurate computation of transpulmonary pressure [2-5]. Transpulmonary pressure is particularly useful in the monitoring of lung overdistention and to set positive end-expiratory pressure (PEEP) [11-13]. However, the body of evidence attesting the reli-

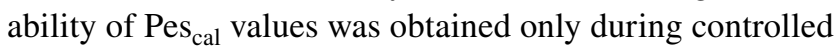
ventilation [10, 14-16], while it remains unclear whether the oesophageal balloon calibration procedure is feasible during invasive assisted ventilation. As matter of fact, during pressure support ventilation (PSV), the patient's respiratory muscles interact with the ventilator in a variable fashion. Consequently, breath-by-breath changes in lung volume and muscular pressure make the oesophageal balloon calibration particularly challenging during PSV.

The primary aim of the present investigation was to assess the feasibility of the oesophageal balloon calibration during PSV. Secondarily, measures obtained by the calibrated approach during PSV were compared to those obtained during volume-controlled ventilation (VCV) as reference.

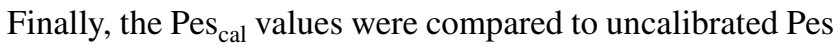
values $\left(\mathrm{Pes}_{\mathrm{V} 4}\right)$ acquired at a filling volume of $4 \mathrm{ml}\left(\mathrm{V}_{4}\right)$, as per manufacturer recommendations.

\section{Methods}

\subsection{Patients}

This analysis was conducted on patients enrolled in a study evaluating the impact of a calibrated approach on oesophageal and transpulmonary pressure monitoring during Sigh breath. The study was approved by ethical committee of "Maggiore della Carità" University Hospital, Novara, Italy (CE 111/18) and registered at www.clinicaltrials.gov, (number NCT03721237). The informed consent was obtained from all subjects, according to local regulations.

Adult patients admitted to ICU with diagnosis of hypoxemic acute respiratory failure [17] and undergoing invasive mechanical ventilation were enrolled. Exclusion criteria were: (1) contraindications to naso-gastric tube placement, (2) pregnancy, (3) history of severe chronic obstructive pulmonary disease, (4) dynamic hyperinflation, (5) hemodynamic instability (i.e. need for continuous infusion of epinephrine or vasopressin, dopamine $>5 \mu \mathrm{g} / \mathrm{kg} / \mathrm{min}$ or norepinephrine $>0.1 \mu \mathrm{g} / \mathrm{kg} / \mathrm{min}$ to maintain systolic arterial blood pressure $\geq 90 \mathrm{mmHg}$ ), (6) previous inclusion in another research protocol.

\subsection{Protocol}

First, during deep sedation (Richmond Agitation Sedation Scale score of - 5), with patients in VCV mode, a special gastric feeding tube equipped with oesophageal balloon
(Nutrivent Sidam, Mirandola, MO, Italy), previously deflated and secured with a three-way stopcock, was inserted through the nose/mouth till the stomach was reached. Afterwards, the balloon was connected through polyethylene tubes to a pressure transducer box (KleisTEK Engineering, Bari, Italy). The balloon was inflated at a volume of $4 \mathrm{ml}$, the intra-gastric position was confirmed by positive deflection during gentle external manual epigastric compression. Subsequently, the catheter was slowly withdrawn into the mid-lower third of oesophagus, as indicated by the appearance of cardiac artefacts on the oesophageal pressure waveform [4]. The calibration procedure was started to identify $\mathrm{V}_{\text {best }}$ : the oesophageal balloon was progressively inflated with increasing volume from 0 to $8 \mathrm{ml}$, assuring a complete deflation before each inflation volume. At each volume, static end-expiratory and end-inspiratory Pes values were acquired by applying inspiratory and expiratory holds of $5 \mathrm{~s}$. Hence, end-expiratory and end-inspiratory Pes to balloon filling volume curves were obtained and analysed. On the end-expiratory curve, the intermediate linear section was graphically identified together with its lower $\left(\mathrm{V}_{\text {min }}\right)$ and upper $\left(\mathrm{V}_{\max }\right)$ inflection points. $\mathrm{V}_{\text {best }}$ was chosen within this range of filling volumes as the smallest one associated with the largest respiratory tidal Pes swing $\left(\Delta \mathrm{Pes}_{\mathrm{T}}\right)$. Then, after the balloon calibration was completed, the validation occlusion test was performed with $\mathrm{V}_{\text {best }}$ and $\mathrm{V}_{4}$, by applying two external compressions on the rib cage during an expiratory hold. Simultaneous deflections of airway ( $\Delta$ Paw) and oesophageal pressure $(\Delta \mathrm{Pes})$ were compared (occlusion validation test) [5, 18-21]: the test was positive if the ratio of oesophageal to airway pressure deflections $(\Delta \mathrm{Pes} / \Delta \mathrm{Paw})$ was in the $0.8-1.2$ range. Afterwards, sedation was reduced (Richmond Agitation Sedation Scale score of $-3 /-2$ ) and, the patients, whenever able to trigger the ventilator, were switched to PSV. The oesophageal balloon was again progressively filled with volumes ranging between 0 and $8 \mathrm{ml}$, deflating it before each volume, and end-expiratory Pes values were collected during 3-s inspiratory and expiratory holds. During the hold, it was mandatory to check for the patient's respiratory muscles relaxation, as proved by a flat and stable plateau of the Pes and airway pressure $[4,5]$. After the end-expiratory Pes to balloon filling volume curve reconstruction and $\mathrm{V}_{\text {min }}$ and $\mathrm{V}_{\text {max }}$ identification [10], at variance from VCV, $\mathrm{V}_{\text {best }}$ was identified as the oesophageal balloon filling volume associated with the highest $\Delta \mathrm{Pes}_{\mathrm{T}}$ to the related tidal volume $\left(\mathrm{V}_{\mathrm{T}}\right)$ ratio $\left(\Delta \mathrm{Pes}_{\mathrm{T}} / \mathrm{V}_{\mathrm{T}}\right)$ (Fig. 1). As a matter of fact, during PSV, the $\mathrm{V}_{\mathrm{T}}$ is not constant as during VCV and absolute $\Delta \mathrm{Pes}_{\mathrm{T}}$ values might not be derived from best filling but rather from larger $\mathrm{V}_{\mathrm{T}}$ [24]. Finally, the occlusion test for validation in actively breathing patients was carried out as previously described to calculate $\Delta \mathrm{Pes} / \Delta \mathrm{Paw}$ ratio at $\mathrm{V}_{\text {best }}$ and $\mathrm{V}_{4}[4,5,21]$.

To calculate $\mathrm{Pes}_{\mathrm{cal}}$, the oesophageal wall reaction was calculated as previously suggested [10]: as balloon 


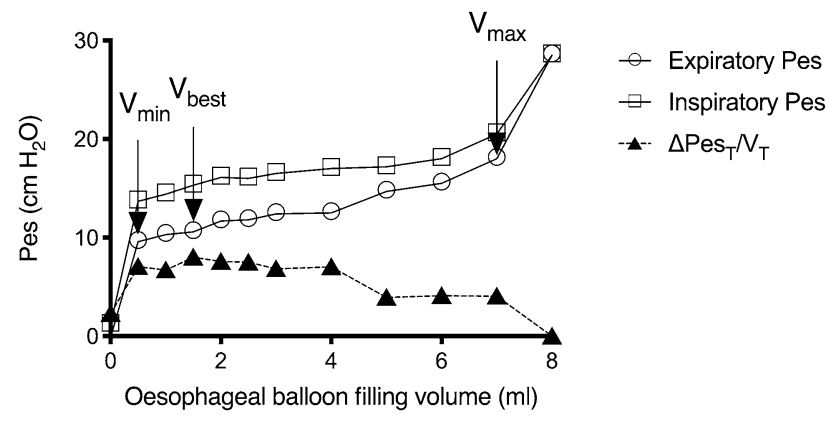

Fig. 1 Oesophageal balloon calibration in pressure support ventilation. Expiratory (hollow circles) and inspiratory Pes (hollow squares) to oesophageal balloon volumes curves are plotted. Also, the tidal Pes swing on tidal volume ratio at each balloon volume injected is depicted. Pes oesophageal pressure, $V_{\min }$ and $V_{\max }$ lower and upper inflection point of the expiratory curve, $V_{\text {best }}$ oesophageal balloon filling volume associated with the highest tidal Pes swing on tidal volume ratio $\left(\Delta \mathrm{Pes}_{\mathrm{T}} / \mathrm{V}_{\mathrm{T}}\right)$

under-filling occurs at volumes lower than $\mathrm{V}_{\min }$, while volumes higher than $\mathrm{V}_{\max }$ induce balloon overstretch [10, 25], oesophageal elastance is computed as the slope of the Pes to balloon volume curve between $\mathrm{V}_{\min }$ and $\mathrm{V}_{\max }[10$, 26]. Accordingly, the actual pressure of oesophageal wall at $\mathrm{V}_{\text {best }}$ is [10]:

Oesophageal wall pressure at $\mathrm{V}_{\text {best }}=\left(\mathrm{V}_{\text {best }}-\mathrm{V}_{\text {min }}\right)$

$\times$ Oesophageal elastance.

Finally, Pes $_{\text {cal }}$ computation is obtained by following equation [10]:

Pes cal $_{\text {cal }}=$ Pes at $\mathrm{V}_{\text {best }}$ - Oesophageal wall pressure at $\mathrm{V}_{\text {best }}$.

Also, end-expiratory and end-inspiratory uncalibrated $\mathrm{Pes}_{\mathrm{V} 4}$ were acquired and collected during VCV and PSV.

Ventilation settings were: (1) during $\mathrm{VCV}, \mathrm{V}_{\mathrm{T}}$ ranged between 6 and $8 \mathrm{ml} / \mathrm{kg}$ of predicted body weight with clinical positive end-expiratory pressure (PEEP), respiratory rate was chosen to maintain an end-tidal carbon dioxide tension of $35-45 \mathrm{mmHg}$, and inspired oxygen fraction was set to achieve a peripheral saturation of 92-96\%; (2) during PSV, with patients able to trigger the ventilator, maintaining the same PEEP and inspired oxygen fraction levels previously set, the pressure support was selected to get $\mathrm{V}_{\mathrm{T}}$ similar to VCV. The sedation plan was managed to achieve a target Richmond Agitation Sedation Scale score of -5 in VCV and $-3 /-2$ in PSV.

In case of hemodynamic instability (i.e., mean arterial blood pressure $<60 \mathrm{mmHg}$ despite fluid bolus), tachyarrhythmia, agitation (i.e., Richmond Agitation Sedation Scale score $>1$ ), oxygen saturation $<90 \%$, peak airway pressure $>40 \mathrm{cmH}_{2} \mathrm{O}$, and increment of the body temperature ( $\geq 38{ }^{\circ} \mathrm{C}$ core) the study protocol was stopped.

\subsection{Measurement}

During all study phases, upon a heated pneumotachograph (Fleisch no. 2; Fleisch, Lausanne, Switzerland) was mounted between endotracheal tube and respiratory circuit, flow and airway pressure were obtained. Esophageal and gastric pressure were acquired through the aforementioned catheter. Subsequently, flow and pressure waveforms in the airway, esophagus, and stomach were recorded, digitalized and collected via a specific acquisition system on a personal computer (ICU Lab, KleisTEK Engineering, Bari, Italy) at each study step. The calibration data were computed through a dedicated sheet (Excel, Microsoft, Washington, USA).

After enrolment, demographic and clinical characteristics such as sex, age, body mass index, predicted body weight, days of mechanical ventilation and admission diagnosis were obtained for each patient.

\subsection{Statistical analysis}

No power calculation was carried out before the study and the sample size was based on the available data from patients enrolled in the trial. Continuous variables are reported as mean and standard deviation. Non-parametric tests were employed to carry out data analysis. Comparison between parameters was assessed using Wilcoxon matched-pairs rank test. Bland-Altman analysis was employed to describe the $\mathrm{Pes}_{\mathrm{v} 4}-\mathrm{Pes}_{\mathrm{cal}}$ difference. In particular, an absolute $\mathrm{Pes}_{\mathrm{v} 4}-\mathrm{Pes}_{\mathrm{cal}}$ difference $>2 \mathrm{cmH}_{2} \mathrm{O}$ and $>5 \mathrm{cmH}_{2} \mathrm{O}$ was considered clinically relevant and potentially harmful, respectively [10]. Categorical variables, whether dichotomous or nominal, were evaluated with a Fisher's exact test. For all the comparisons $\mathrm{p}$ values $<0.05$ were considered statistically significant. Statistical analyses were conducted using Prism 6.0 software (Graph-pad, California-USA).

\section{Results}

From November 2018 to May 2019, 21 patients were enrolled and finally analysed for a total of 42 complete calibration procedures, 21 in VCV and 21 in PSV, respectively (Fig. 2). Demographic characteristics are presented in Table 1, while the mechanical ventilation settings are reported in Table 2.

Figure 3 depicts the results from the occlusion tests during VCV and PSV. $\Delta$ Pes/ $\Delta$ Paw was $0.97 \pm 0.12$ at $\mathrm{V}_{\text {best }}$ vs. $1.24 \pm 0.47$ at $\mathrm{V}_{4}$ during VCV $(\mathrm{p}=0.0108$ ) (Fig. 3a), while no significant difference was detected between the two volumes during PSV $(0.91 \pm 0.1$ vs. $0.88 \pm 0.21, p=0.7012)$ (Fig. 3c). However, while at $\mathrm{V}_{\text {best }} \Delta \mathrm{Pes} / \Delta \mathrm{Paw}$ ranged 


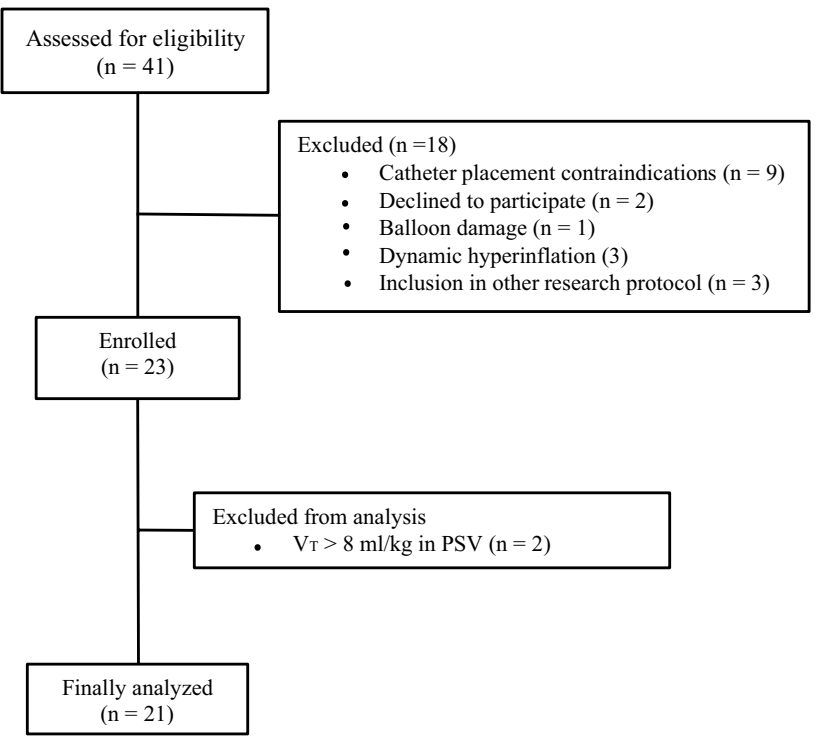

Fig. 2 Enrollment flow diagram. $V_{T}$ Tidal volume, $P S V$ pressure support ventilation

Table 1 Demographic characteristics

Table 2 Mechanical ventilation settings invasive mechanical ventilation, $A R D S$ acute respiratory distress syndrome
Data are presented in number and percentage (in brackets) or mean and standard deviation

$B M I$ Body Mass Index, $P B W$

\begin{tabular}{|c|c|}
\hline Patients & $(\mathrm{n}=21)$ \\
\hline Male sex, no (\%) & $15(71.4 \%)$ \\
\hline Age, years & $57 \pm 17$ \\
\hline BMI, $\mathrm{kg} / \mathrm{m}^{2}$ & $28.5 \pm 6.6$ \\
\hline PBW, kg & $67.4 \pm 9.7$ \\
\hline Days of iMV & $7.3 \pm 4.3$ \\
\hline Pneumonia, no (\%) & $6(28.6 \%)$ \\
\hline ARDS, no (\%) & $15(71.4 \%)$ \\
\hline \multicolumn{2}{|c|}{$\begin{array}{l}\text { Data are presented in number } \\
\text { and percentage (in brackets) or } \\
\text { mean and standard deviation }\end{array}$} \\
\hline \multicolumn{2}{|c|}{$\begin{array}{l}B M I \text { Body Mass Index, } P B W \\
\text { predicted body weight, } i M V \\
\text { invasive mechanical ventilation, } \\
\text { ARDS acute respiratory distress } \\
\text { syndrome }\end{array}$} \\
\hline
\end{tabular}

between 0.8 and 1.2 in all patients both during VCV and PSV, at $\mathrm{V}_{4}$ only $12 / 21(57 \%)$ during VCV $(\mathrm{p}=0.0013)$ (Fig. 3b) and 11/21 (52\%) subjects during PSV $(p=0.0005)$ (Fig. 3d) passed the occlusion test.

As expected, $\Delta \mathrm{Pes}_{\mathrm{T}}$ during $\mathrm{VCV}$ and $\Delta \mathrm{Pes}_{\mathrm{T}} / \mathrm{V}_{\mathrm{T}}$ during PSV were higher at $\mathrm{V}_{\text {best }}$ Vs. those computed at $\mathrm{V}_{4}$ $\left(\Delta \mathrm{Pes}_{\mathrm{T}}, 2.9 \pm 1.2 \mathrm{cmH}_{2} \mathrm{O}\right.$ vs. $1.9 \pm 1.2 \mathrm{cmH}_{2} \mathrm{O} ; \Delta \mathrm{Pes}_{\mathrm{T}} / \mathrm{V}_{\mathrm{T}}$, $7.7 \pm 3.8 \mathrm{cmH}_{2} \mathrm{O} / \mathrm{l}$ vs. $4.5 \pm 2.7 \mathrm{cmH}_{2} \mathrm{O} / \mathrm{l} ; \mathrm{p}<0.0001$ for both comparisons).

In Table 3 are reported the data from calibrated and uncalibrated approach for Pes assessment during VCV and PSV. $V_{\min }, V_{\text {max }}$, and $V_{\text {best }}$ remained unchanged at each study step. The oesophageal elastance did not differ between the two ventilatory modes and oesophageal wall pressure was similar during VCV and PSV at both $\mathrm{V}_{\text {best }}$ and $\mathrm{V}_{4}$. Nevertheless, irrespective from the ventilation mode, the oesophageal wall pressure was higher at $\mathrm{V}_{4}$ compared to that computed at $\mathrm{V}_{\text {best }}$ (during VCV, $\mathrm{p}=0.0006$; during PSV, $\mathrm{p}<0.0001$ ). End-expiratory and end-inspiratory $\mathrm{Pes}_{\mathrm{v} 4}$ were significantly higher compared to Pes ${ }_{\text {cal }}$ during both study phases ( $\mathrm{p}<0.0001$ for all comparisons).

Difference between $\mathrm{Pes}_{\mathrm{V} 4}$ and $\mathrm{Pes}_{\mathrm{cal}}$ at both end-expiration and end-inspiration are reported in Figs. 4 and 5 (Bland-Altman analyses). End-expiratory $\mathrm{Pes}_{\mathrm{V} 4}-\mathrm{Pes}_{\mathrm{cal}}$ difference was $4.9 \pm 2 \mathrm{cmH}_{2} \mathrm{O}$ during VCV (Fig. 4a) and $5.8 \pm 2.3 \mathrm{cmH}_{2} \mathrm{O}$ during PSV ( $\left.\mathrm{p}=0.0175\right)$ (Fig. 4b). During both ventilation modes, this difference could be considered clinically relevant in the totality (100\%) of cases. In addition, it was deemed potentially harmful in 10/21 (48\%) patients during VCV and 12/21 (57\%) during PSV. At end-inspiration, $\mathrm{Pes}_{\mathrm{V} 4}-\mathrm{Pes}_{\mathrm{cal}}$ difference during VCV was $4 \pm 1.5 \mathrm{cmH}_{2} \mathrm{O}$ (Fig. 5a), while during PSV was $4.6 \pm 1.9$ $\mathrm{cmH}_{2} \mathrm{O}(\mathrm{p}=0.1790)$ (Fig. 5b). This difference reached clinical relevance in 19/21 (90\%) cases during VCV and 20/21 (95\%) during PSV. Moreover, it was potentially harmful in 6/21 (29\%) and 9/21 (43\%) cases during VCV and PSV, respectively. . 
A

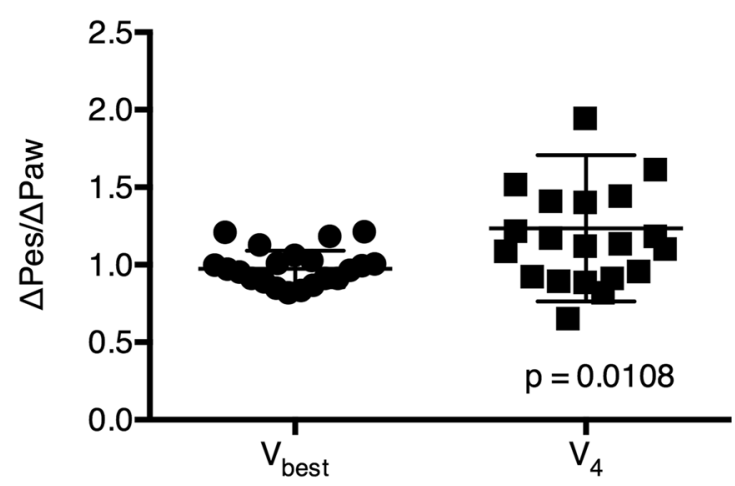

C

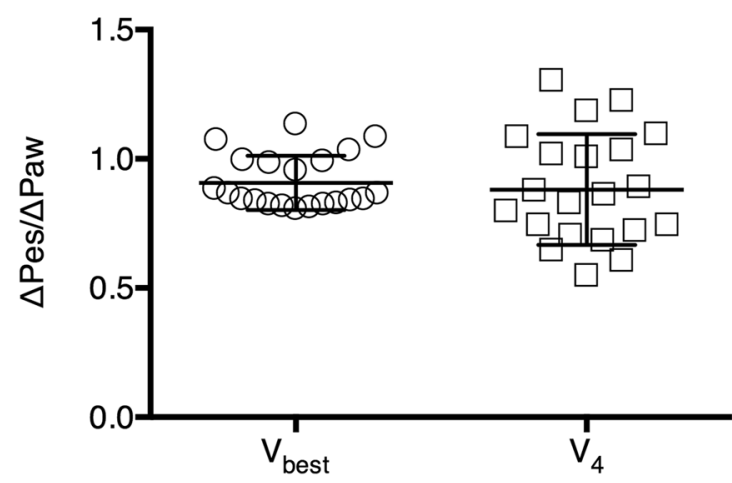

Fig. 3 Validation occlusion test. a Volume-controlled ventilation mode: $\Delta$ Pes/Paw of each subject at $\mathrm{V}_{\text {best }}$ (solid circles) and $\mathrm{V}_{4}$ (solid squares) are plotted. Also, the overall mean and standard deviation at $\mathrm{V}_{\text {best }}$ and $\mathrm{V}_{4}$ are depicted; $\triangle$ Pes/Paw oesophageal pressure deflection to airway pressure deflection, $V_{\text {best }}$ optimal oesophageal balloon filling volume, $V_{4}$ filling volume of $4 \mathrm{ml}$ as per manufacturer recommendations. b Volume-controlled ventilation mode: number of subjects who passed or not the validation occlusion test at $\mathrm{V}_{\text {best }}$ (black bars) and $\mathrm{V}_{4}$ (grey bars), respectively. $\mathrm{V}_{\text {best }}$, optimal oesophageal balloon filling volume; $\mathrm{V}_{4}$, filling volume of $4 \mathrm{ml}$ as per manufacturer recom-

\section{Discussion}

The main findings of present investigation can be summarized as follows: (1) the oesophageal balloon calibration was feasible during PSV; (2) as opposed to the recommended filling volume, the optimal volume selected by the calibrated approach resulted in significant more patients with positive occlusion test; (3) $\mathrm{V}_{\text {best }}$ during PSV was similar to the one employed in VCV with the same PEEP and similar $\mathrm{V}_{\mathrm{T}}$; (4) $\mathrm{Pes}_{\mathrm{V} 4}$ was overestimated compared to $\mathrm{Pes}_{\mathrm{cal}}$ at both end-expiration and end-inspiration because of a more pronounced oesophageal wall reaction elicited by the uncalibrated conventional approach.

Oesophageal balloon calibration has been employed to increase accuracy of Pes assessment in passive patient undergoing invasive controlled mechanical ventilation [10].
B

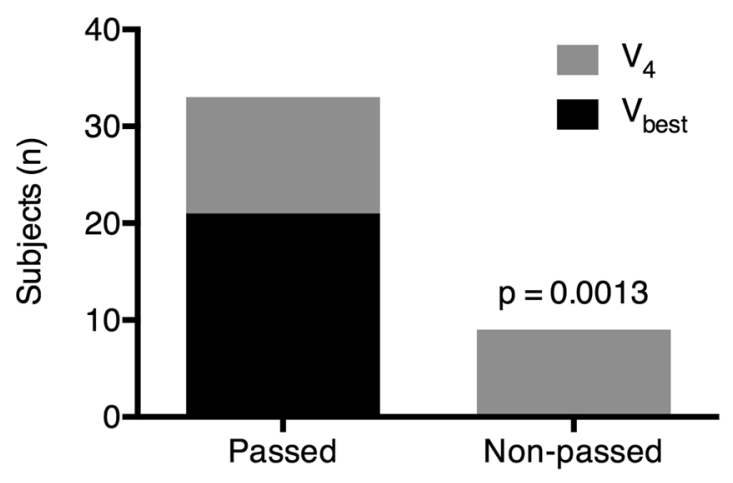

D

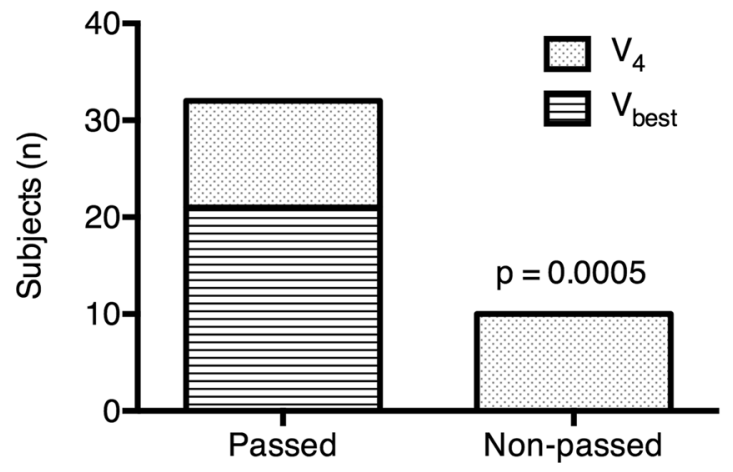

mendations. c Pressure support ventilation mode: $\Delta$ Pes/Paw of each subject at $\mathrm{V}_{\text {best }}$ (hollow circles) and $\mathrm{V}_{4}$ (hollow squares) are plotted. Also, the overall mean and standard deviation at $\mathrm{V}_{\text {best }}$ and $\mathrm{V}_{4}$ are depicted; $\Delta$ Pes/Paw, oesophageal pressure deflection to airway pressure deflection; $\mathrm{V}_{\text {best }}$, optimal oesophageal balloon filling volume; $\mathrm{V}_{4}$, filling volume of $4 \mathrm{ml}$ as per manufacturer recommendations. d Volume-controlled ventilation mode: number of subjects who passed or not the validation occlusion test at $\mathrm{V}_{\text {best }}$ (striped bars) and $\mathrm{V}_{4}$ (dotted bars), respectively. $V_{\text {best }}$, optimal oesophageal balloon filling volume; $\mathrm{V}_{4}$, filling volume of $4 \mathrm{ml}$ as per manufacturer recommendations

This is a 2-steps procedure consisting of (1) identification of optimal balloon filling volume in the presence of a constant tidal volume (2) correction for oesophageal wall reaction and balloon elastic recoil. PSV is the most used ventilation mode that implies an interaction between patient's muscles and the ventilator with consequent breath-to-breath variability of tidal volume. Thus, the oesophageal balloon calibration is particularly challenging during PSV because of the patient's active contribution to respiration. In particular, high respiratory rate and the impossibility to assure respiratory muscle relaxation during an occlusion hinder the calibration process during assisted ventilation $[4,5]$. Taking into account all of these, we conducted the present study in selected patients, and we described that it was possible to obtain extemporary muscle relaxation during holds in all of them. Thus, we performed a series of complete oesophageal pressure 
Table 3 Oesophageal balloon calibration

\begin{tabular}{lcrr}
\hline Parameters & \multicolumn{2}{l}{ Study steps } & \\
\cline { 2 - 4 } & \multicolumn{1}{l}{$\mathrm{VCV}$} & PSV & p value \\
\hline $\mathrm{V}_{\min }(\mathrm{ml})$ & $0.5 \pm 0.2$ & $0.5 \pm 0.2$ & $>0.9999$ \\
$\mathrm{~V}_{\max }(\mathrm{ml})$ & $6 \pm 1$ & $6.2 \pm 1.3$ & 0.9910 \\
$\mathrm{~V}_{\text {best }}(\mathrm{ml})$ & $1.9 \pm 1.6$ & $1.7 \pm 1.6$ & 0.5217 \\
Oesophageal elastance $\left(\mathrm{cmH}_{2} \mathrm{O} / \mathrm{ml}\right)$ & $1.6 \pm 0.7$ & $1.6 \pm 0.6$ & 0.7854 \\
Oesophageal wall pressure at $\mathrm{V}_{\text {best }}\left(\mathrm{cmH}_{2} \mathrm{O}\right)$ & $1.7 \pm 2.1 *$ & $1.8 \pm 2.1 *$ & $>0.9999$ \\
Oesophageal wall pressure at $\mathrm{V}_{4}\left(\mathrm{cmH}_{2} \mathrm{O}\right)$ & $5.5 \pm 2.5$ & $5.7 \pm 2.3$ & $>0.9999$ \\
End-expiratory $\mathrm{Pes}_{\text {cal }}\left(\mathrm{cmH}_{2} \mathrm{O}\right)$ & $8.5 \pm 2.9 *$ & $8.9 \pm 3.4^{*}$ & $>0.9999$ \\
End-expiratory $\mathrm{Pes}_{\mathrm{V} 4}\left(\mathrm{cmH}_{2} \mathrm{O}\right)$ & $13.4 \pm 3.4$ & $14.7 \pm 4.2$ & 0.3840 \\
End-inspiratory $\mathrm{Pes}_{\text {cal }}\left(\mathrm{cmH}_{2} \mathrm{O}\right)$ & $11.4 \pm 3^{*}$ & $12.4 \pm 3.9 *$ & $>0.9999$ \\
End-inspiratory $\mathrm{Pes}_{\mathrm{V} 4}\left(\mathrm{cmH}_{2} \mathrm{O}\right)$ & $15.4 \pm 3$ & $17 \pm 3.9$ & 0.9093
\end{tabular}

Data are reported as mean and standard deviation

$V_{\min }$ minimal oesophageal filling volume, $V_{\max }$ maximal oesophageal filling volume, $V_{\text {best }}$ optimal oesophageal filling volume, $\mathrm{V}_{4}, P e s_{c a l}$ calibrated oesophageal pressure at $\mathrm{V}_{\text {best }}$, Pes $\mathrm{V}_{V 4}$ uncalibrated oesophageal pressure at an oesophageal balloon filling volume equal to $4 \mathrm{ml}$, as per manufacturer recommendations, $V C V$ volume-controlled ventilation, $P S V$ pressure support ventilation

${ }^{*} p<0.05$, calibrated technique vs. uncalibrated conventional approach with $4 \mathrm{ml}$-filling volume calibration, as previously described, in 21 patients for a total of 42 procedures, 21 during $\mathrm{VCV}$, as a reference, and 21 during PSV. Moreover, for each calibration procedure, all of the volumes previously proposed for this specific balloon employed could be explored. Description of the feasibility of such calibration manoeuvre during PSV might greatly improve clinical use of calibrated oesophageal pressure values, with more precise assessment of transpulmonary pressure and the risk of self-inflicted lung injury.

The validation occlusion test is the reference method to validate in clinical practice accuracy of Pes measures [5]. During this test, the optimal position and filling volume of the oesophageal balloon is cleared when simultaneous Pes and Paw swings of equal entity are observed [21]. Recently, it has been demonstrated that, in intubated acute respiratory failure subjects undergoing $\mathrm{VCV}, \mathrm{V}_{\text {best }}$ (i.e., the filling volume with largest $\Delta \mathrm{Pes}_{\mathrm{T}}$ ) allowed to achieve the best $\Delta \mathrm{Pes} /$ $\Delta$ Paw value and the higher occlusion test success rate, as compared other oesophageal balloon filling volumes, like the one recommended by the manufacturer [10]. In line with these findings, here we show that when $\mathrm{V}_{\text {best }}$ was employed during VCV and PSV, the percentage of subjects who passed the test was higher compared to $\mathrm{V}_{4}$. In terms of reproducibility, at $\mathrm{V}_{\text {best }}$, the $\Delta$ Pes $/ \Delta$ Paw values we obtained during VCV and PSV corresponded to those measured in intubated non-paralyzed subjects with an optimally located oesophageal balloon [19]. However, at variance from the $\Delta \mathrm{Pes} / \Delta \mathrm{Paw}$ reduction observed moving from VCV to PSV by Chiumello et al. [27], in our population the ratio remained substantially unchanged. This could be explained by the fact that for Pes assessment we applied a calibrated approach to correct for artefacts both during controlled and assisted ventilation. In our series, the occlusion test carried out at $\mathrm{V}_{4}$ performed worse than that observed at $\mathrm{V}_{\text {best }}$ because the average $\Delta$ Pes/ $\triangle$ Paw during VCV almost reached 1.2, the defined upper limit of failure. Finally, the occlusion test success rate at $\mathrm{V}_{4}$ ranged between 60 and $50 \%$ during both modes, confirming previous findings [10].

$\mathrm{V}_{\text {best }}$ was the volume associated with optimal transmission of $\Delta \mathrm{Pes}_{\mathrm{T}}$ in passively ventilated patients. In our study, during PSV, $\mathrm{V}_{\text {best }}$ was chosen as the filling volume able to maximize the $\Delta \mathrm{Pes}_{\mathrm{T}} / \mathrm{V}_{\mathrm{T}}$ ratio and was compared to that observed during VCV. Average $\mathrm{V}_{\text {best }}$ was similar among the two ventilation modes and was always lower than the recommended volume of $4 \mathrm{ml}$. This might have been the consequence of different factors: (1) the $\mathrm{V}_{\mathrm{T}}$ range target was similar during VCV and PSV; (2) no modifications of the mechanical properties of the respiratory system occurred during the two study steps; (3) sedation was tailored switching from VCV to PSV to achieve and maintain the prefixed target of $\mathrm{V}_{\mathrm{T}}$ during assisted breath. Thus, $\mathrm{V}_{\text {best }}$ selected during VCV might be used during PSV if $\mathrm{V}_{\mathrm{T}}$ and PEEP remain similar.

In our series, $\mathrm{V}_{\text {best }}$ was lower than volumes previously reported in ICU patients $[10,28]$. However, in one study [28], the oesophageal balloon volume was chosen according to previous evaluations obtained in vitro rather than by accurate calibration. In the other [10], the demographic characteristics of study population (i.e. higher body mass index) and ventilator settings (i.e. higher PEEP) could explain the difference in $\mathrm{V}_{\text {best }}$ observed.

Pes $_{\text {cal }}$ computation requires the correction for the artefacts deriving from the oesophageal wall reaction and the balloon recoil pressure [10]. Consequently, uncalibrated Pes is 
A

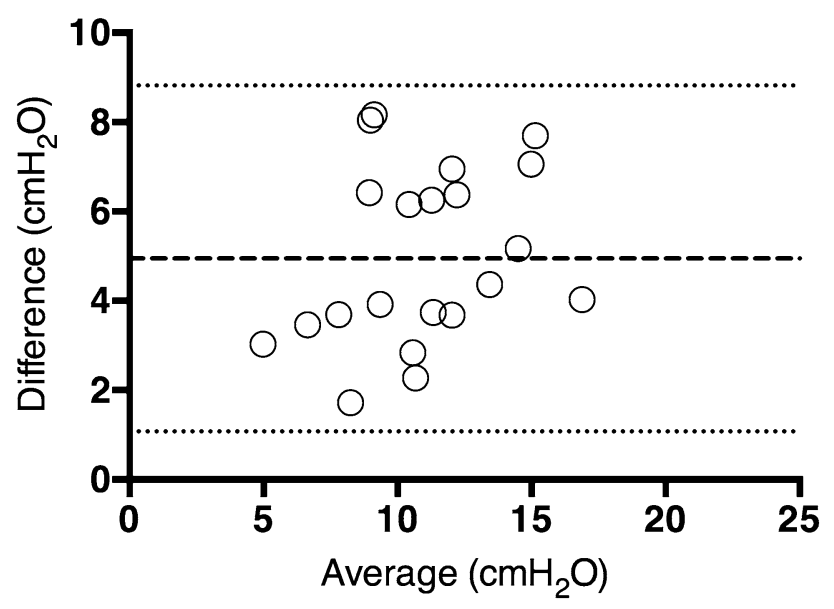

B

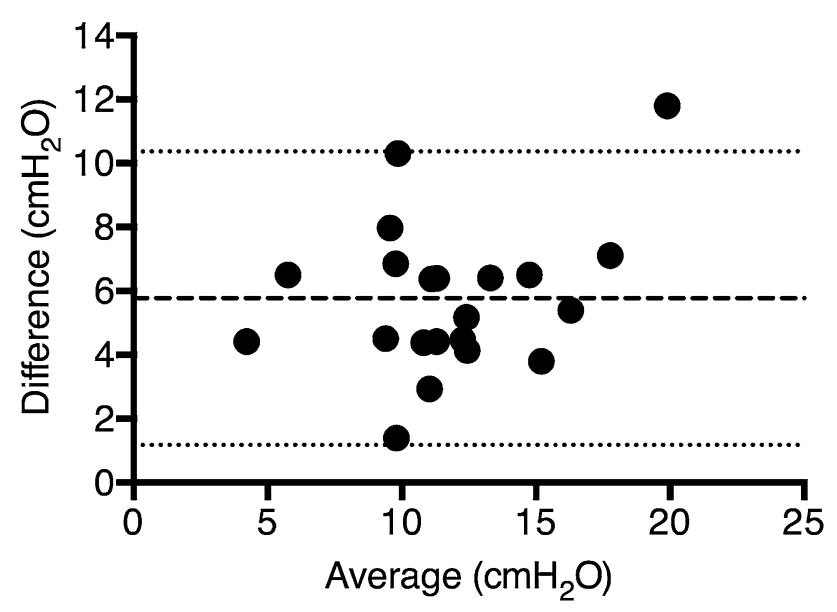

Fig. 4 Bland-Altmann analysis of calibrated and uncalibrated endexpiratory oesophageal pressure. Bias and agreement are represented for each graph. a Hollow circles, volume-controlled ventilation; bias $4.9 \mathrm{cmH}_{2} \mathrm{O}, 95 \%$ limits of agreement from 1.1 to $8.8 \mathrm{cmH}_{2} \mathrm{O}$. b Solid circles, pressure support ventilation; bias $5.8 \mathrm{cmH}_{2} \mathrm{O}, 95 \%$ limits of agreement from 1.2 to $10.4 \mathrm{cmH}_{2} \mathrm{O}$

usually overestimated in respect to the calibrated one [10, $14,25]$. In keeping with previous works [10, 14, 25], in our investigation, $\mathrm{Pes}_{\mathrm{V} 4}$ was higher than $\mathrm{Pes}_{\mathrm{cal}}$ during both controlled and assisted ventilation because $\mathrm{V}_{4}$ induced a greater oesophageal wall reaction compared to $\mathrm{V}_{\text {best }}$. The $\mathrm{Pes}_{\mathrm{V} 4}-\mathrm{Pes}_{\mathrm{cal}}$ difference was analysed at both end-expiration and end-inspiration. This frequently exceeded the threshold indicated for clinical relevance and potential harm at both end-expiration and end-inspiration, respectively. This might have a relevant impact in respiratory monitoring and mechanical ventilation settings: in the presence of a filling volume of $4 \mathrm{ml}$, mistakes regarding measure of lung overdistention and the PEEP selection in course of Pes-driven ventilation could frequently occur $[12,29,30]$.
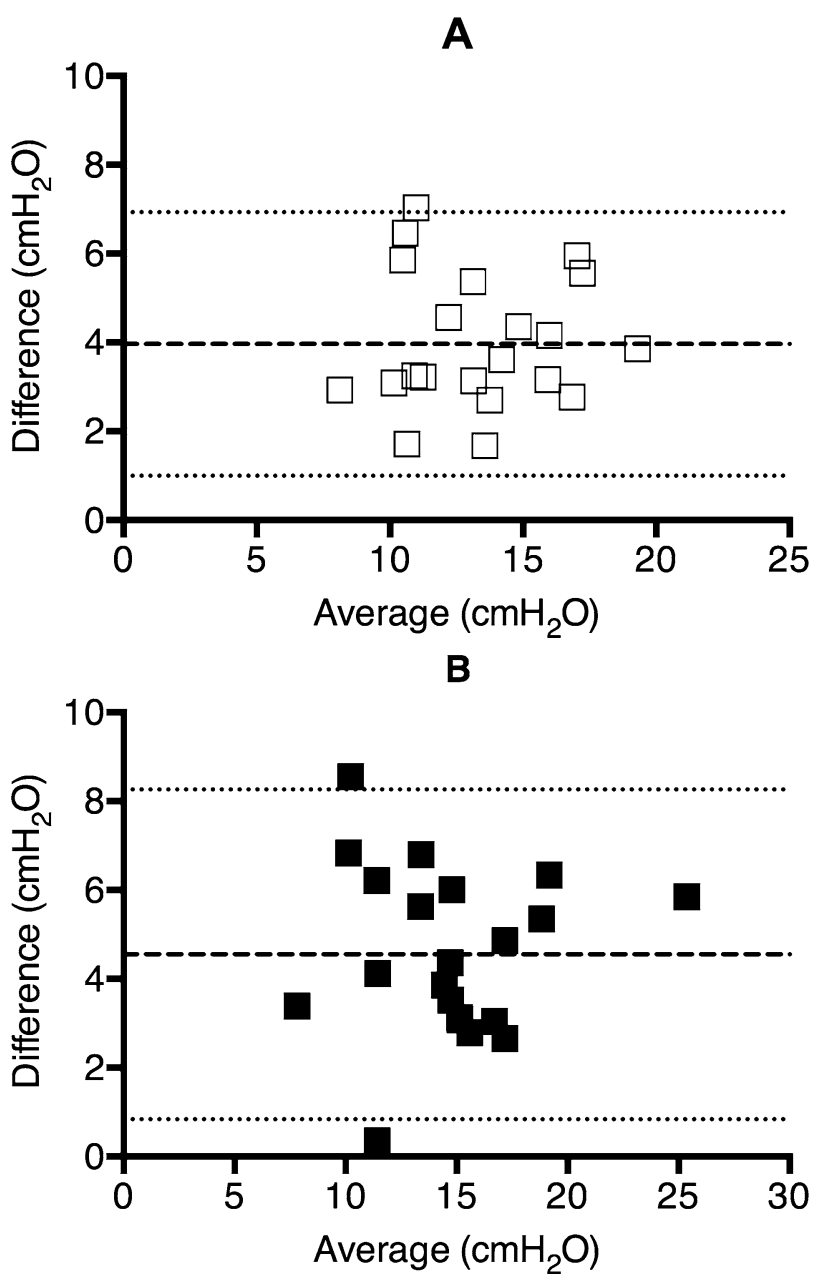

Fig. 5 Bland-Altmann analysis of calibrated and uncalibrated endinspiratory oesophageal pressure. Bias and agreement are represented for each graph. a Hollow squares, volume-controlled ventilation; bias $4 \mathrm{cmH}_{2} \mathrm{O}, 95 \%$ limits of agreement from 1 to $6.9 \mathrm{cmH}_{2} \mathrm{O}$. b Solid squares, pressure support ventilation; bias $4.6 \mathrm{cmH}_{2} \mathrm{O}, 95 \%$ limits of agreement from 0.8 to $8.3 \mathrm{cmH}_{2} \mathrm{O}$

Several limitations require to be disclosed. First, this study has a relatively small sample size; however, our study population size is line with the "rule of thumbs" recommendations referring to the pilot study planning [31]. Second, only one type of Pes catheter was employed. Nevertheless, the device employed in our investigation has been widely used in previous clinical and bench studies [8, $10,29,32]$. Moreover, the device employed in our study is a polyfunctional catheter combining a feeding tube with the oesophageal balloon [28] that might represent the easiest for clinical implementation of Pes. Lastly, the Pes calibration requires to obtain a flat and stable plateau in the different pressure traces during holds [10, 22], but, in spontaneously breathing patients with high respiratory drive, relaxation might be difficult to obtain [23]. Sedation 
might have played a key role in our study as we obtained relaxation in all patients, indeed, the effects of sedation on the breathing pattern and neural drive have been welldocumented in course of assisted ventilation [33, 34].

\section{Conclusions}

The oesophageal balloon calibration is feasible in ICU patients undergoing PSV and allows to obtain a reliable Pes assessment also in this setting. Further investigations are needed to evaluate the impact of its application in different clinical conditions.

Acknowledgements The present investigation has been conducted employing institutional funding (Department of Translational Medicine, Università del Piemonte Orientale, Novara, Italy) for oesophageal catheters purchasing.

Funding Prof. Paolo Navalesi reports grants, personal fees and nonfinancial support from Maquet Critical Care, grants and non-financial support from Draeger, grants and non-financial support from Intersurgical S.p.A, personal fees from Oriopharma, personal fees from Philips, personal fees from Resmed, personal fees from MSD, personal fees from Novartis, outside the submitted work. In addition, Prof. Navalesi has a patent helmet Next with royalties paid to Intersurgical Spa, and a patent EP20170199831 pending. Prof. Pesenti reports personal fees from Maquet, personal fees from Xenios, personal fees from Baxter, personal fees from Boehringer Ingelheim, outside the submitted work. Dr. Mauri reports personal fees from Drager, personal fees from Fisher and Paykel, outside the submitted work.

\section{Compliance with ethical standards}

Conflict of interest No conflict of interest exists for Gianmaria Cammarota, Federico Verdina, Erminio Santangelo, Gianluigi Lauro, Ester Boniolo, Riccardo Tarquini, Elena Spinelli, Eugenio Garofalo, Andrea Bruni, Francesco Della Corte, and Rosanna Vaschetto.

\section{References}

1. Brochard L, Martin GS, Blanch L, Pelosi P, Belda FJ, Jubran A, et al. Clinical review: respiratory monitoring in the ICU-a consensus of 16. Crit Care. 2012;16:219.

2. Loring SH, Topulos GP, Hubmayr RD. Transpulmonary pressure: the importance of precise defi nitions and limiting assumptions. Am J Respir Crit Care Med. 2016;194:1452-7.

3. Grieco DL, Chen L, Brochard L. Transpulmonary pressure: importance and limits. Ann Transl Med. 2017;5:285.

4. Mauri T, Yoshida T, Bellani G, Goligher EC, Carteaux G, Rittayamai $\mathrm{N}$, et al. Esophageal and transpulmonary pressure in the clinical setting: meaning, usefulness and perspectives. Intensive Care Med. 2016;42:1360-73.

5. Akoumianaki E, Maggiore SM, Valenza F, Bellani G, Jubran A, Loring SH, et al. The application of esophageal pressure measurement in patients with respiratory failure. Am J Respir Crit Care Med. 2014;189:520-31.

6. Loring SH, O’Donnell CR, Behazin N, Malhotra A, Sarge T, Ritz R, et al. Esophageal pressures in acute lung injury: do they represent artifact or useful information about transpulmonary pressure, chest wall mechanics, and lung stress? J Appl Physiol. 2010;108:515-22.

7. Hedenstierna G. Esophageal pressure: benefit and limitations. Minerva Anestesiol. 2012;78:959-66.

8. Mojoli F, Chiumello D, Pozzi M, Algieri I, Bianzina S, Luoni S, et al. Esophageal pressure measurements under different conditions of intrathoracic pressure. An in vitro study of second generation balloon catheters. Minerva Anestesiol. 2015;81:855-64.

9. Milic-Emili J, Mead J, Turner JM, Glauser EM. Improved technique for estimating pleural pressure from esophageal balloons. J Appl Physiol. 1964;19:207-11.

10. Mojoli F, Iotti GA, Torriglia F, Pozzi M, Volta CA, Bianzina S, et al. In vivo calibration of esophageal pressure in the mechanically ventilated patient makes measurements reliable. Crit Care. 2016;20:98.

11. Umbrello M, Chiumello D. Interpretation of the transpulmonary pressure in the critically ill patient. Ann Transl Med. 2018;6:383.

12. Talmor D, Sarge T, Malhotra A, O’Donnell CR, Ritz R, Lisbon A, et al. Mechanical ventilation guided by esophageal pressure in acute lung injury. N Engl J Med. 2008;359:2095-104.

13. Grasso S, Terragni P, Birocco A, Urbino R, Del Sorbo L, Filippini C, et al. ECMO criteria for influenza A (H1N1)-associated ARDS: role of transpulmonary pressure. Intensive Care Med. 2012;38:395-403.

14. Sun XM, Chen GQ, Huang HW, He X, Yang YL, Shi ZH, et al. Use of esophageal balloon pressure-volume curve analysis to determine esophageal wall elastance and calibrate raw esophageal pressure: a bench experiment and clinical study. BMC Anesthesiol. 2018;18:1-9.

15. Yang Y-L, He X, Sun X-M, Chen H, Shi Z-H, Xu M, et al. Optimal esophageal balloon volume for accurate estimation of pleural pressure at end-expiration and end-inspiration: an in vitro bench experiment. Intensive Care Med Exp. 2017;5:35.

16. Hotz JC, Sodetani CT, Van Steenbergen J, Khemani RG, Deakers TW, Newth CJ. Measurements obtained from esophageal balloon catheters are affected by the esophageal balloon filling volume in children with ARDS. Respir Care. 2018;63:177-86.

17. Ranieri VM, Rubenfeld GD, Thompson BT, Ferguson ND, Caldwell E, Fan E, et al. Acute respiratory distress syndrome: the Berlin definition. JAMA. 2012;307:2526-33.

18. Lanteri CJ, Kano S, Sly PD. Validation of esophageal pressure occlusion test after paralysis. Pediatr Pulmonol. 1994;17:56-62.

19. Higgs BD, Behrakis PK, Bevan DR, Milic Emili J. Measurement of pleural pressure with esophageal balloon in anesthetized humans. Anesthesiology. 1983;59:340-3.

20. D'Angelo E, Robatto FM, Calderini E, Tavola M, Bono D, Torri G, et al. Pulmonary and chest wall mechanics in anesthetized paralyzed humans. J Appl Physiol. 1991;70:2602-10.

21. Baydur A, Behrakis PK, Zin WA, Jaeger M, Milic-Emili J. A simple method for assessing the validity of the esophageal balloon technique. Am Rev Respir Dis. 1982;126:788-91.

22. Bellani G, Grasselli G, Teggia-Droghi M, Mauri T, Coppadoro A, Brochard L, et al. Do spontaneous and mechanical breathing have similar effects on average transpulmonary and alveolar pressure? A clinical crossover study. Crit Care. 2016;20:142.

23. Younes M, Webster K, Kun J, Roberts D, Masiowski B. A method for measuring passive elastance during proportional assist ventilation. Ajrccm. 2001;164:50-60.

24. MacIntyre NR. Respiratory function during pressure support ventilation. Chest. Am Coll Chest Phys. 1986;89:677-83.

25. Mojoli F, Torriglia F, Orlando A, Bianchi I, Arisi E, Pozzi M. Technical aspects of bedside respiratory monitoring of transpulmonary pressure. Ann Transl Med. 2018;6:377. 
26. Hedenstierna G, Järnberg PO, Torsell L, Gottlieb I. Esophageal elastance in anesthetized humans. J Appl Physiol. 1983;54:1374.

27. Chiumello D, Consonni D, Coppola S, Froio S, Crimella F, Colombo A. The occlusion tests and end-expiratory esophageal pressure: measurements and comparison in controlled and assisted ventilation. Ann Intensive Care. 2016;6:1-10.

28. Chiumello D, Gallazzi E, Marino A, Berto V, Mietto C, Cesana $\mathrm{B}$, et al. A validation study of a new nasogastric polyfunctional catheter. Intensive Care Med. 2011;37:791-5.

29. Yoshida T, Amato MBP, Grieco DL, Chen L, Lima CAS, Roldan R, et al. Esophageal manometry and regional transpulmonary pressure in lung injury. Am J Respir Crit Care Med. 2018;15:1018-26.

30. Chiumello D, Carlesso E, Cadringher P, Caironi P, Valenza F, Polli F, et al. Lung stress and strain during mechanical ventilation for acute respiratory distress syndrome. Am J Respir Crit Care Med. 2008;178:346-55.

31. Julious SA. Sample size of 12 per group rule of thumb for a pilot study. Pharm Stat. 2005;4:287-91.
32. Persson P, Ahlstrand R, Gudmundsson M, De Leon A, Lundin S. Detailed measurements of oesophageal pressure during mechanical ventilation with an advanced high-resolution manometry catheter. Crit Care. 2019;23:1-12.

33. Costa R, Navalesi P, Cammarota G, Longhini F, Spinazzola G, Cipriani F, et al. Remifentanil effects on respiratory drive and timing during pressure support ventilation and neurally adjusted ventilatory assist. Respir Physiol Neurobiol. 2017;244:10-6.

34. Vaschetto R, Cammarota G, Colombo D, Longhini F, Grossi F, Giovanniello A, et al. Effects of propofol on patient-ventilator synchrony and interaction during pressure support ventilation and neurally adjusted ventilatory assist. Crit Care Med. 2014;42:74-82.

Publisher's Note Springer Nature remains neutral with regard to jurisdictional claims in published maps and institutional affiliations. 